\title{
Analysis and Design of a Soft-Switched PWM Sepic DC-DC Converter
}

\author{
In-Dong Kim ${ }^{\dagger}$, Jin-Young Kim*, Eui-Cheol Nho*, and Heung-Geun Kim** \\ $\dagger *$ Dept. of Electrical Eng., Pukyong National University, Busan, Korea \\ ${ }^{* *}$ Dept. of Electrical Eng., Kyungpook National University, Daegu, Korea
}

\begin{abstract}
This paper proposes a new soft-switched Sepic converter. It has low switching losses and low conduction losses due to its auxiliary communicated circuit and synchronous rectifier operation, respectively. Because of its positive and buck/boost-like DC voltage transfer function $(\mathrm{M}=\mathrm{D} /(1-\mathrm{D}))$, the proposed converter is desirable for use in distributed power systems. The proposed converter has versions both with and without a transformer. The paper also suggests some design guidelines in terms of the power circuit and the control loop for the proposed converter.
\end{abstract}

Key Words: DC-DC Converter, Sepic Converter, Soft switching, ZVS (Zero Voltage Switching)

\section{INTRODUCTION}

In terms of converters with both buck and boost functions, there exist several converters such as basic the buck-boost converter and the Cuk, Zeta, and Sepic converters [1]-[8]. In other words these converters have in common the fact that their DC voltage transfer characteristics are equal to:

$$
\frac{V_{O}}{V_{i}}=\frac{D}{1-D}
$$

where $V_{i}, V_{O}$, and $D$ are the DC input voltage, the DC output voltage and the duty cycle, respectively.

Among them the Sepic converter has the relatively good features that follow:

1) The polarities of the input and output voltage are the same from the same ground reference.

2) The input current riple is low due to the existence of large input inductor.

3) A version with a transformer exists so that the galvanic isolation between the input and output side is possible.

Thanks to these good characteristics, the Sepic converter seems to be a good candidate for the use in power factor correction, solar cell converters, fuel cell converters, etc.

Therefore, this paper proposes a new soft-switched Sepic converter. The proposed converter not only has low switching losses but also low conduction losses due to its zero voltage switching and its synchronous rectifier operation. Furthermore, thanks to the positive and buck/boost-like DC voltage transfer function $(\mathrm{M}=\mathrm{D} /(1-\mathrm{D}))$, the proposed converter is desirable for

\footnotetext{
Manuscript received May 6, 2010; revised Jul. 20, 2010

† Corresponding Author: idkim@pknu.ac.kr

Tel: +82-51-629-6318, Fax: +82-51-629-6305, Pukyong Nat. Univ.

* Dept. of Electrical Eng., Pukyong National University, Korea

** Dept. of Electrical Eng., Kyungpook National University, Korea
}

use in distributed power systems. The proposed converter also has versions both with and without a transformer.

\section{PROPOSED ZVS PWM SEPIC DC-DC CONVERTER}

A power stage circuit diagram of the proposed converter is shown in Fig. 1.

The circuit can be divided into two parts, that is, the hardswitched Sepic dc-dc converter and the auxiliary resonant commutated pole circuit [9]. The hard-switched Sepic dc-dc converter is the skeleton of the proposed converter. Fig. 1 includes a MOSFET switch $S_{2}$ only to achieve synchronous rectification, but not for a backward power flow like a Zeta converter. The main switches $S_{1}$ and $S_{2}$ switch on and off with the anti-parallel connected diodes $D_{1}$ and $D_{2}$, respectively, carrying out synchronous rectifier operation. The inductor current through $L_{1}$ and $L_{2}$ are positive for the forward power flow.

The auxiliary resonant commutated pole circuit (ARCPC) is composed of a small MOSFET Sa, and a resonant inductor $L_{r}$. The ARCPC circuit provides the hard-switched Sepic dc-dc

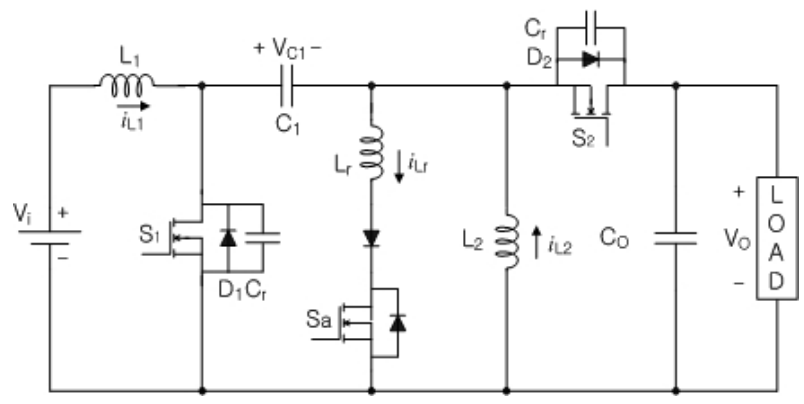

Fig. 1. Proposed ZVS PWM Sepic DC-DC converter. 


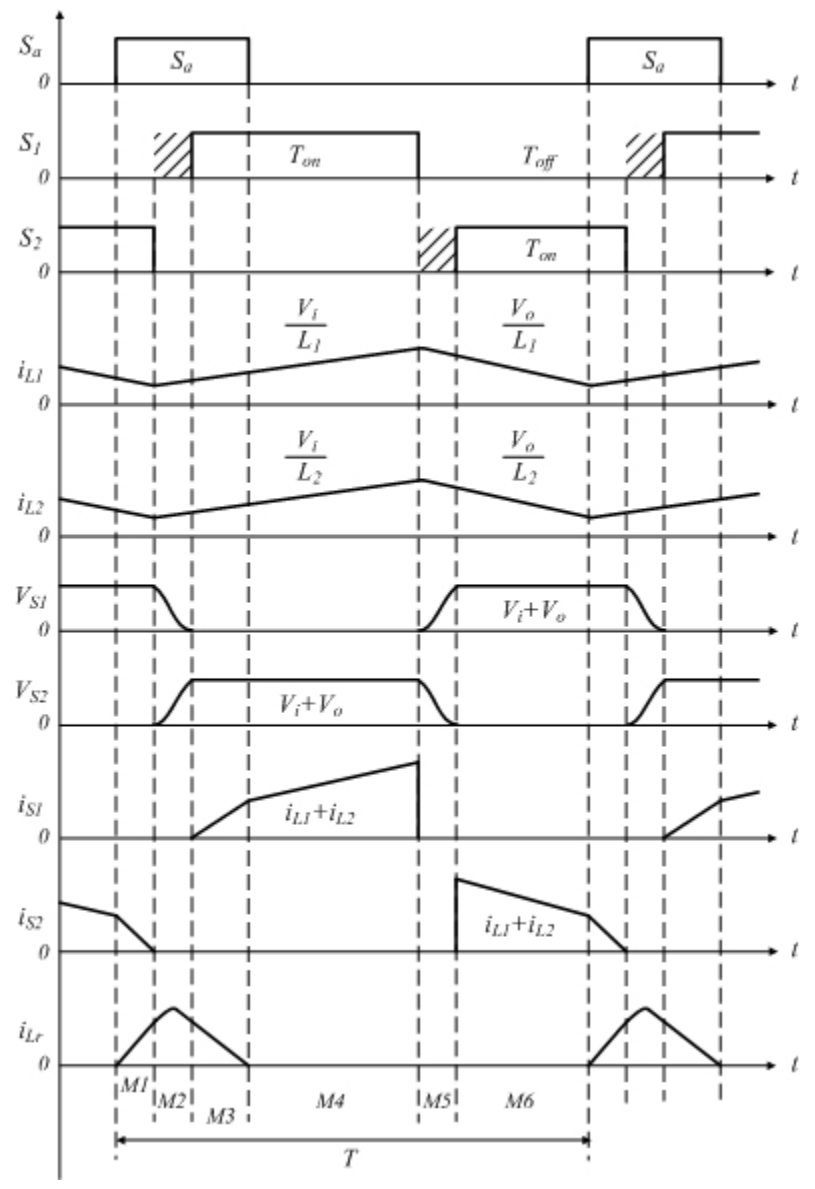

Fig. 2. Operating waveforms of the proposed converter.

converter with ZVS operation, and it is rated for a small power when compared with the output power. The ZVS operation for both the main MOSFET devices and the diodes results in improved circuit efficiency. Furthermore, since the ZVS switching occurs during a short time when compared to the switching period, it does not have a significant influence on the overall output characteristics of the basic DC/DC converter such as the PWM control and the linear input and output conversion characteristics.

The proposed converter has its operating waveforms as shown in Fig. 2.

When looking into the operation of the proposed converter in greater detail, its operation can be divided into 6 operation modes for one switching period, as shown in Fig. 3.

\section{DESIGN OF THE PROPOSED ZVS PWM SEPIC DC-DC CONVERTER}

In order to verify the effectiveness of the proposed converters and to suggest design guidelines for real applications, a prototype converter is properly designed with a rated power of $1.0[\mathrm{~kW}]$, a controlled output voltage of $100[\mathrm{~V}]$, an input voltage range of $4060[\mathrm{~V}]$, and a switching frequency $40[\mathrm{kHz}]$ above the acoustic noise frequency.

The proposed converter has an auxiliary resonant commutated pole circuit (ARCPC) composed of a small MOSFET $S_{a}$, and a resonant inductor $L_{r}$. However, the auxiliary circuit has little effect on the overall PWM operation characteristics
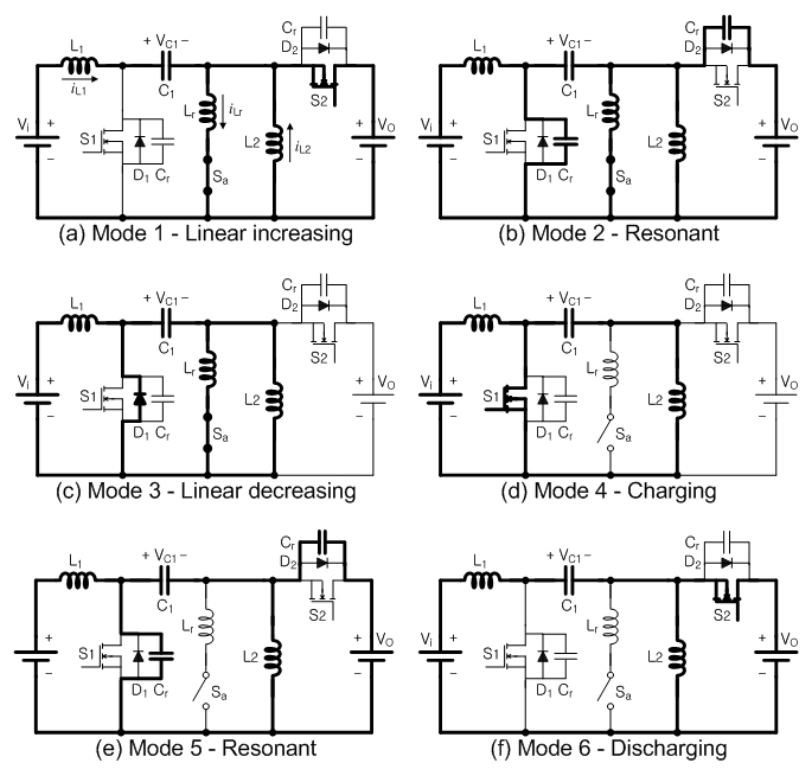

Fig. 3. Operating modes of the proposed converter.

of the hard switching PWM Sepic converter. Therefore, in the steady-state, the average values of the inductor voltages $v_{L 1}$ and $v_{L 2}$ are equal to zero, resulting in the following equation (1):

$$
V_{i}=V_{C 1} .
$$

The voltage across the inductor $L_{2}$ during the on-state time $T_{o n}$ and the off-state time $T_{o f f}$ of the switch $S_{1}$ is $V_{i}$ and $V_{O}$, respectively. Since the flux increment of the inductor $L_{2}$ during the on-state time is equal to its flux decrement during the off-state time. Therefore, the following equation can be obtained:

$$
d V_{i}=V_{O}(1-d)
$$

Thus, the voltage conversion ration $V_{O} / V_{i}$ of the proposed ZVS Sepic converter can be expressed as:

$$
\frac{V_{O}}{V_{i}}=\frac{d}{1-d}
$$

where the duty cycle d of the switch $S_{1}$ can be defined as $d=T_{o n} / T$ where $T_{o n}$ and $T$ are the on-state time and the switching period of the switch $S_{1}$, respectively.

In addition, as the steady-state power balance is satisfied:

$$
V_{i} I_{L 1}=V_{O} I_{O}
$$

Thus:

$$
\frac{V_{O}}{V_{i}}=\frac{I_{L 1}}{I_{O}} .
$$

By combining equations (3) and (5), we can get the following equation (6): 


$$
\frac{I_{L 1}}{I_{O}}=\frac{d}{1-d} .
$$

On the other hand, when $S_{2}$ is in the on-state, the inductor currents $I_{L 1}$ and $I_{L 2}$ flow together through $S_{2}$ to the output side, and thus the following equation can be obtained:

$$
I_{O}=\left(I_{L 1}+I_{L 2}\right)(1-d) .
$$

From equations (6) and (7):

$$
I_{L 2}=\frac{1-d}{d} I_{L 1}=I_{O}
$$

Since the input voltage ranges from $40[\mathrm{~V}]$ to $60[\mathrm{~V}]$ and the output voltage is to be controlled to $100[\mathrm{~V}]$, the variation range of the duty cycle $\mathrm{d}$ in the practical converter control is as follows:

$$
0.63<d<0.71 \text {. }
$$

In this condition, the average current value $I_{L 1 \text {.avg }}$ through the inductor $L_{1}$ has its maximum value at $d=0.71$, being expressed as:

$$
I_{L 2 . a v g}=\frac{1000[W]}{40[V]}=25[A] .
$$

By using the above derived equation (8), the maximum value of the average inductor current through $L_{2}$ is $I_{L 2 \text {.avg }}=$ $15[A]$. When considering a ripple factor of $25 \%$ in the inductor current through $L_{1}$ and $L_{2}$, the maximum current value $I_{s . \max }$ of the switches $S_{1}$ and $S_{2}$ is given as:

$$
I_{\text {s.max }}=1.25\left(I_{L 1 . \text { avg }}+I_{L 2 . a v g}\right)=50[A] .
$$

On the other hand, the switch voltage $V_{S 1}$ across $S_{1}$ is:

$$
V_{S 1}=V_{i}+V_{O}=160[A] .
$$

Thus, MOSFETs IXFN130N30 with a rated current of $130[\mathrm{~A}]$ and a rated voltage of $300[\mathrm{~V}]$ are selected for the experimental prototype by considering a design margin of $100 \%$.

The current waveform through $L_{1}$ at a duty cycle $\mathrm{d}$ of $2 / 3$ is shown in Fig. 4 and the peak-to-peak value $\Delta I_{L 1}$ of the current ripple through $L_{1}$ is given as (13).

$$
\Delta I_{L 1}=\frac{V_{i}}{L_{1}} T_{o n}
$$

When limiting the peak-to-peak current value $\Delta I_{L 1}$ to within $25 \%$ of the rated current:

$$
\Delta I_{L 1}=\frac{50[\mathrm{~V}]}{L_{1}} \times 25[\mu \mathrm{sec}] \times \frac{2}{3}=25[\mathrm{~A}] \times 0.25 .
$$

Thus, by solving (14) and considering the design margin, the designed circuit parameter of the inductor $L_{1}$ is selected

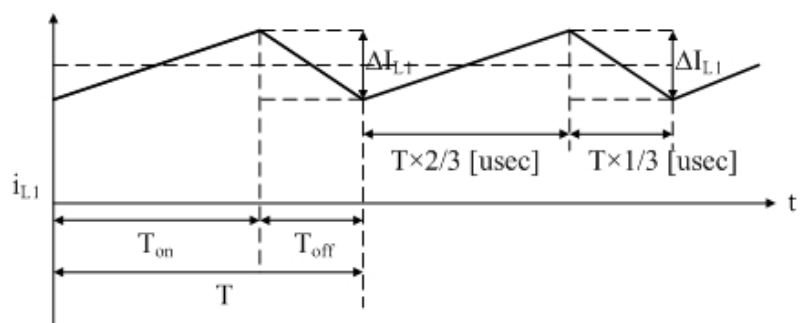

Fig. 4. Inductor current $i_{L 1}$ at $\mathrm{d}=2 / 3$.

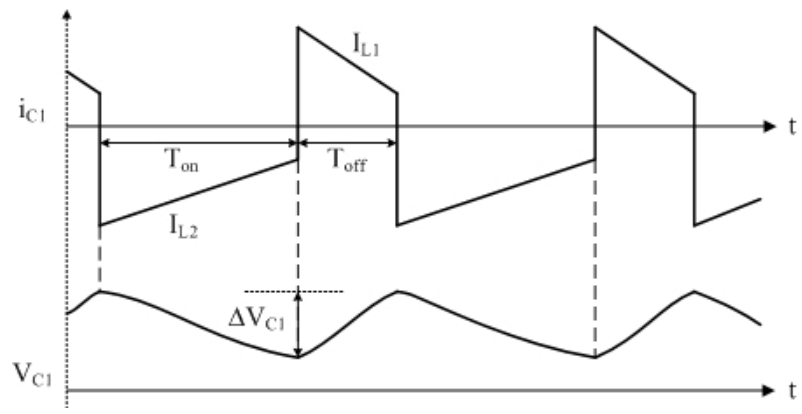

Fig. 5. Current waveform $i_{C 1}$ and voltage waveform $V_{C 1}$ of capacitor $C_{1}$.

as $133[\mathrm{uH}]$ with an average current of $25[\mathrm{~A}]$. In addition, the circuit parameter of $L_{2}$ is also selected to be equal to that of $L_{1}$, but with an average current of 15[A]. The inductors should not be designed for the average current but for the peak current.

When neglecting the circuit influence of the ARCPC, the voltage and current waveforms of $C_{1}$ are shown as Fig. 5 and the peak-to-peak voltage value $\Delta V_{C 1}$ of capacitor $C_{1}$ can be given as (15).

$$
\Delta V_{C 1}=\frac{1}{C 1} I_{L 2} \times T_{o n}
$$

To limit the peak-to-peak voltage value $\mathrm{VC} 1$ to within $25 \%$ of the input voltage, $C_{1}$ should be selected as a polypropylene capacitor of $40[\mathrm{uF}], 12$ [Arms].

Fig. 6 shows the current waveform $I_{S 2}$ through the switch $S_{2}$ and the voltage waveform $V_{O}$ across the output capacitor $C_{2}$. The peak-to-peak voltage value $\Delta V_{O}$ of the output capacitor $C_{2}$ is derived as (16).

$$
\Delta V_{O}=\frac{1}{C_{2}}\left(I_{S 2}-I_{O}\right)\left(T-T_{o n}\right) .
$$

To limit the peak-to-peak value $\Delta V_{O}$ to within $1 \%$ of the predetermined output voltage, the output capacitor should be selected as $C_{2}=470[\mathrm{uF}]$.

The ripple current of the output capacitor $C_{2}$ can be calculated as (17)

$$
I_{C 2 . \text {.ripple }}=\sqrt{\frac{1}{T} \int_{0}^{T} i_{C 2}^{2} d t}=17[A] .
$$

Thus, the output capacitor $\mathrm{C} 2$ should be designed as 470 [uF], 17 [Arms].

To ensure ZVS operation of the switches $S_{1}$ and $S_{2}$, the auxiliary circuit parameters $C_{r}$ and $L_{r}$ of the ARCPC are 


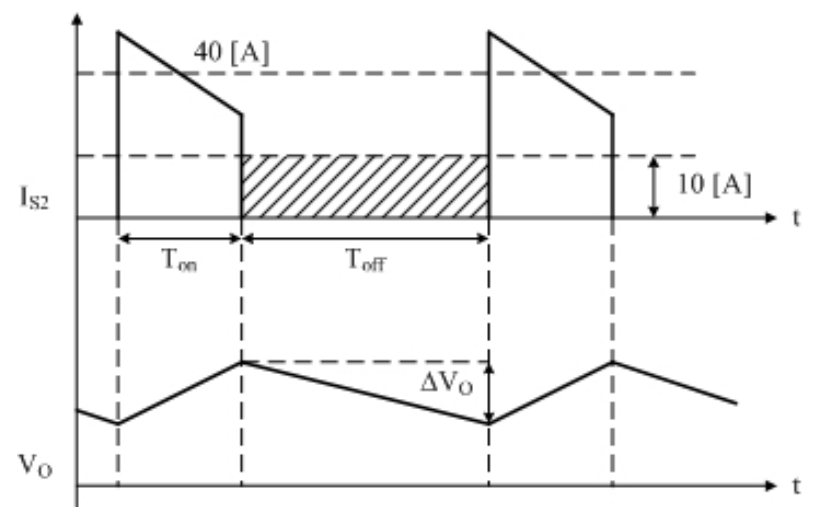

Fig. 6. Current waveform $I_{S 2}$ of MOSFET $S_{2}$ and voltage waveform $V_{O}$ of capacitor $C_{2}$.

selected as $23.5[\mathrm{nF}]$ and $10[\mathrm{uH}]$, respectively, according to conventional design rules.

Upon turning on the auxiliary switch $S_{a}$ the auxiliary inductor current $i_{L r}$ increases linearly with the rising slope of (18).

$$
\frac{d i_{L r}}{d t}=\frac{V_{O}}{L_{r}}=\frac{100[\mathrm{~V}]}{10[\mu H]}=10[\mathrm{~A} / \mu \mathrm{sec}] .
$$

When $i_{D 2}=40[A]$, the time interval $\Delta t_{1}$ of mode 1 is given as (19).

$$
\Delta t_{1}=\frac{40[A]}{20}=2[\mu \mathrm{sec}] .
$$

On the other hand, the resonant period $T_{r}$ of the auxiliary resonant parameters $C_{r}$ and $L_{r}$ is given as (20).

$$
T_{r}=\frac{1}{f_{r}}=2 \pi \sqrt{L_{r} C_{r}} .
$$

Thus, the time interval $\Delta t_{2}$ of mode 2 can be calculated as (21).

$$
\Delta t_{2}=\frac{T_{r}}{4}=0.75[\mu \mathrm{sec}] .
$$

In addition, the rising increment $\Delta i_{L r}$ of the auxiliary inductor current $i_{L r}$ during mode 2 is equal to (22).

$$
\Delta i_{L r}=\frac{V_{i}+V_{O}}{\sqrt{\frac{L_{r}}{C_{r}}}}=\frac{160}{\sqrt{\frac{10[\mu H]}{23.5[\mu F]}}}=7.75[A] .
$$

At the beginning point $t_{3}$ of mode 3 , the auxiliary inductor current $i_{L r}$ is equal to $i_{L r}\left(t_{3}\right)=45[A]$. It takes $\Delta t_{3}$ as (23) until the auxiliary inductor current $i_{L r}$ is reduced to zero.

$\Delta t_{3}=\frac{i_{L r}\left(t_{3}\right)}{\frac{d i_{L r}}{d t}}=\frac{i_{L r\left(t_{3}\right)}}{\frac{V_{i}}{L_{r}}}=\frac{45[A]}{60[V] / 5[\mu F]}=3.75[\mu \mathrm{sec}]$.

Switching timing diagrams of the main switches $S_{1}, S_{2}$. and the auxiliary switches $S_{a}$ are shown as Fig. 7 to ensure the ZVS operation of the main switches and the ZCS operation of the auxiliary switches. The crossing point of the reference

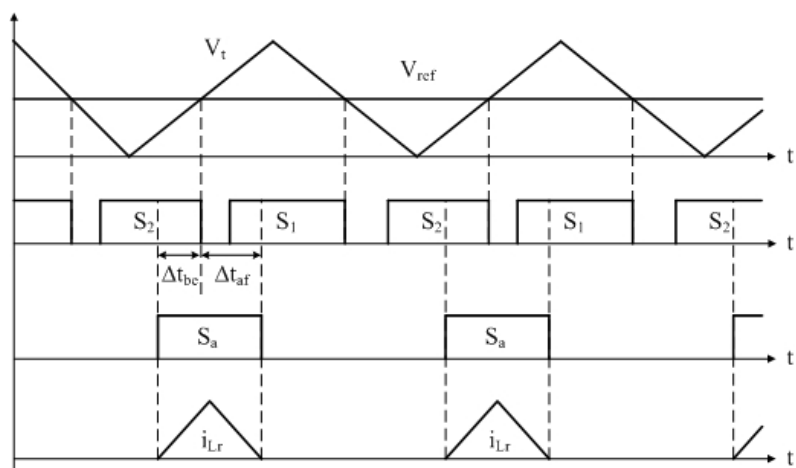

Fig. 7. Switching timing of switches $S_{a}$ for ZVS Switching.

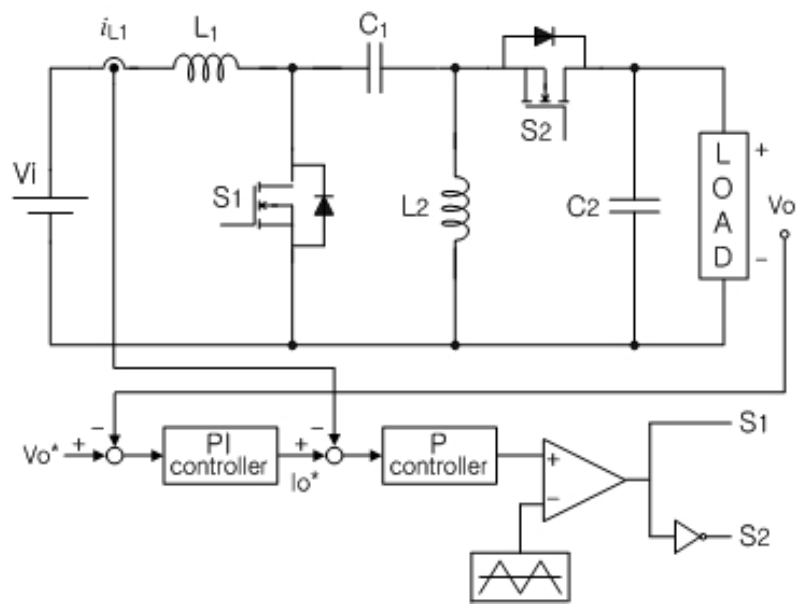

Fig. 8. Control block diagram of the proposed converter.

PWM signal and the triangular carrier is the criterion point to turn on and off the main and auxiliary switches.

As shown in Fig. 7, at the up slope of the triangular carrier, the auxiliary switch $S_{a}$ is turned on $\Delta t_{b e}$ before the crossing point, thus increasing the stored energy in the auxiliary inductor. The stored inductor energy enables the ZVS turn-off operation of the switch $S_{2}$. After the resonant operation, it also enables the ZVS turn-on operation of the switch $S_{1}$.

Finally, after the stored energy is discharged to zero, the auxiliary switch $S_{a}$ is turned off $\Delta t_{a f}$ after the crossing point. In the prototype, $\Delta t_{b e}$ and $\Delta t_{a f}$ are properly selected as 2 [usec] and 4 [usec] considering the time intervals $\Delta t_{1}, \Delta t_{2}, \Delta t_{3}$ of mode 1,2 , and 3 .

\section{CONTROL LOOP DESIGN AND SIMULATION OF THE PWM SEPIC DC-DC CONVERTER}

Fig. 8 shows an overall control block diagram of the proposed converter under the assumption that the auxiliary circuit has little effect on the overall PWM operation characteristics of the proposed PWM Sepic converter. The control block diagram consists of two feedback loops, that is, an inner current loop and an outer voltage loop.

The inductor current control loop as an inner control loop is composed of a $\mathrm{P}$ current controller, a PWM generator, a DC/DC converter, and an inductor $L_{1}$. It functions to control the inductor current $I_{L 1}$ and to generate the reference voltage 
TABLE I

COMPONENT PARAMETERS FOR EXPERIMENTAL RESULTS

\begin{tabular}{|c|c|c|c|}
\hline Power rating & $1.0[\mathrm{~kW}]$ & fs & $40[\mathrm{kHz}]$ \\
\hline$V_{1}$ & $40-60[\mathrm{~V}]$ & $V_{2}$ & $100[\mathrm{~V}]$ \\
\hline$C_{1}$ & $40[\mathrm{uF}]$ & $C_{2}$ & $470[\mathrm{uF}]$ \\
\hline$L_{1}$ & $133[\mathrm{uH}]$ & $L_{2}$ & $133[\mathrm{uH}]$ \\
& $25[\mathrm{~A}]$ & & $15[\mathrm{~A}]$ \\
\hline \multicolumn{2}{|c|}{ MOSFET } & \multicolumn{1}{|c|}{ IXYS IXFN130N30 } \\
\hline
\end{tabular}
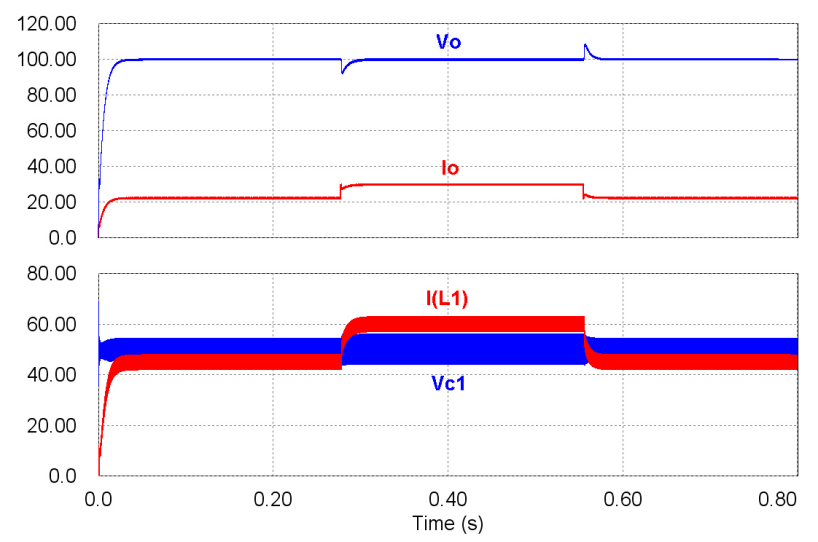

Fig. 9. The output voltage $V_{O}$ and current $I_{O}$ the inductor current $i_{L 1}(t)$ and capacitor voltage $V_{C 1}(t)$ when the load changes from $75 \%$ of the rated power to full power, and back to $75 \%$ of the rated power.

of the PWM generator which supplies the PWM gate signal to each MOSFET switch. Generally a $\mathrm{P}$ controller is enough to ensure the stability of the current loop of the inner loop and to improve the loop bandwidth, but an I controller is not necessary as the steady state error does not affect the system performance. The current reference is obtained from the voltage control loop of the outer loop.

On the other hand the output voltage loop as an outer control loop is to regulate the output voltage $V_{O}$ and to generate the current command for the inner current loop. The voltage control loop is composed of a PI voltage controller, a current control loop, an output capacitor $C_{2}$, and a load. Generally a PI controller is utilized to ensure the stability of the outer voltage loop and to improve the loop bandwidth. In the case of the outer voltage control loop the I controller is necessary as the steady state error does affect the system performance.

In order to verify the operation of the proposed PWM Sepic dc-dc converter, a prototype converter was properly simulated with a rated power of $1.0[\mathrm{~kW}]$, an output voltage of $100[\mathrm{~V}]$ and an input voltage of $4060[\mathrm{~V}]$. Detailed converter ratings and circuit parameters are shown in TABLE I. The simulated converter is controlled through the PWM operation with a carrier frequency of $40[\mathrm{kHz}]$.

An overall control block diagram of the proposed converter is shown in Fig. 8.

The upper graph of Fig. 9 shows the output voltage $V_{O}$ and the current $I_{O}$ when the load changes from $75 \%$ of the rated power to the rated power, and then back to $75 \%$ of the rated power. The lower graph of Fig. 9 shows the inductor current $i_{L 1}(t)$ and the capacitor voltage $V_{C 1}(t)$ under the same operation conditions. As shown in Fig. 9 the proposed converter operates very well with a low output voltage deviation.

Fig. 10 shows the output voltage $V_{O}$, the inductor current $i_{L 1}(t)$ and the capacitor voltage $V_{C 1}(t)$ when the input voltage

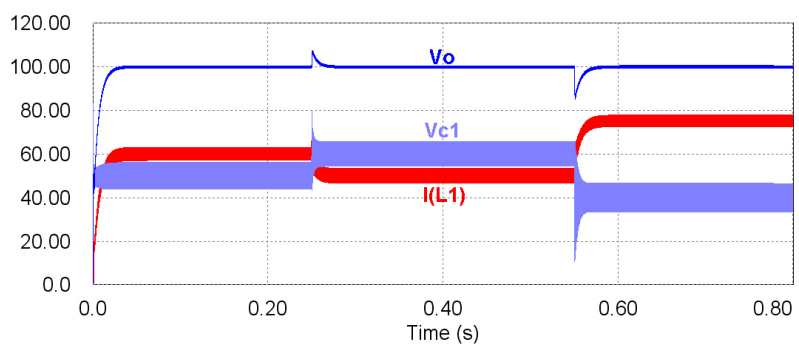

Fig. 10. The output voltage $V_{O}$, the inductor current $i_{L 1}(t)$ and capacitor voltage $V_{C 1}(t)$ when the input voltage changes from $50[\mathrm{~V}]$ to $60[\mathrm{~V}]$, and back to $40[\mathrm{~V}]$.
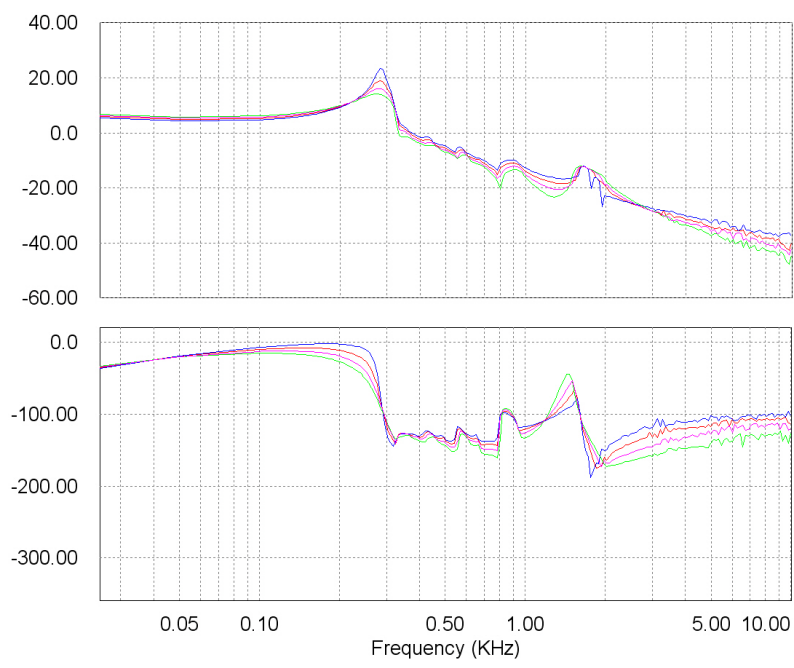

Fig. 11. The Bode plots of the inner current loop gain when the output load power vary from light load(25\%) to full load(100\%).
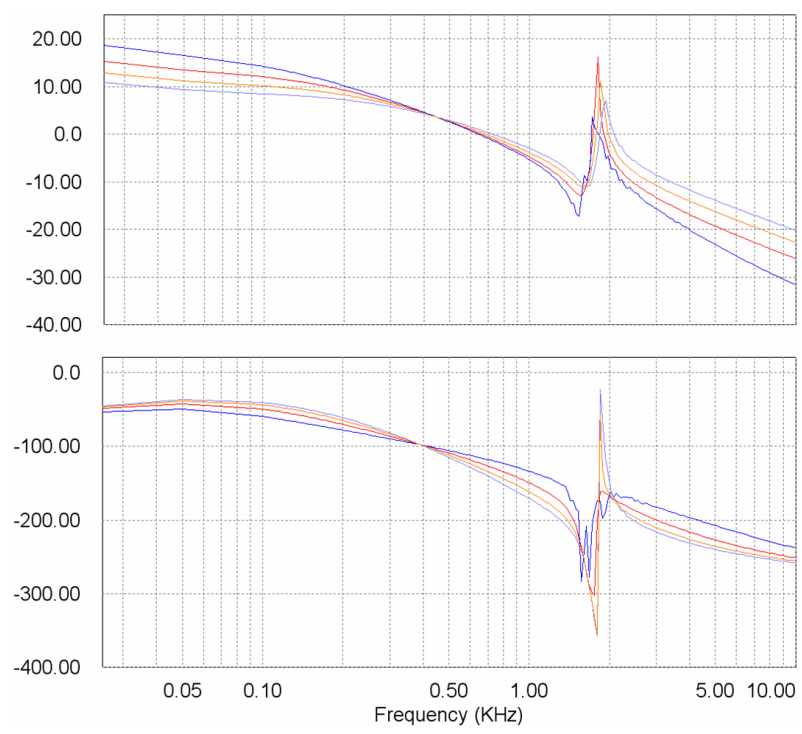

Fig. 12. The Bode plots of the outer voltage loop gain when the output load power vary from light load(25\%) to full load(100\%).

changes from $50[\mathrm{~V}]$ to $60[\mathrm{~V}]$, and then to $40[\mathrm{~V}]$. It proves that the proposed converter operates very well under variations of the input voltage $V_{i}$.

Fig. 11 and Fig. 12 show the Bode plots of the inner current loop gain and the outer voltage loop gain, respectively when the output load power varies from light load to full load. The 


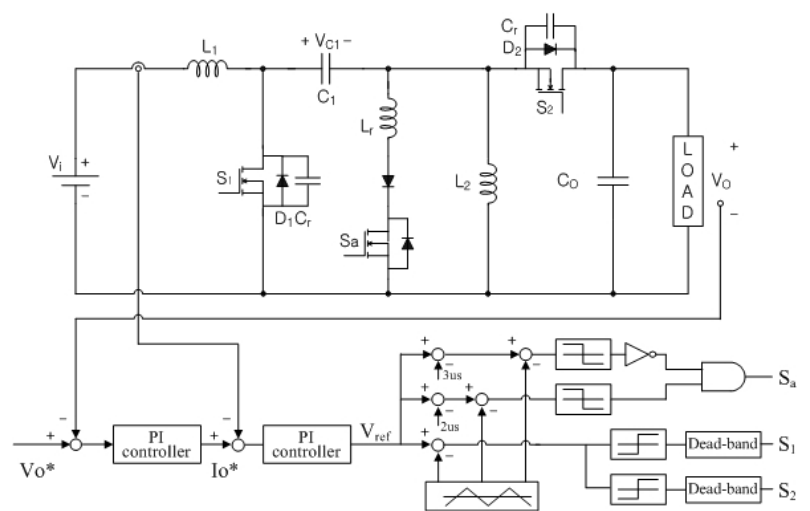

Fig. 13. Control block diagram of the proposed converter.

$\mathrm{P}$ controller and the PI controller were designed with the use of Bode plots according to the traditional method of control loop design.

\section{EXPERIMENTAL RESULTS}

In order to verify the operation of the proposed ZVS PWM Sepic dc-dc converter, a prototype converter was properly implemented with a rated power of $1.0[\mathrm{~kW}]$, an output voltage of $100[\mathrm{~V}]$ and an input voltage of $4060[\mathrm{~V}]$. The detailed converter ratings and circuit parameters are shown in TABLE I. The prototype converter is controlled through PWM operation with a carrier frequency of $40[\mathrm{kHz}]$.

Fig. 13 shows an overall control block diagram of the proposed converter implemented with a DSP controller TMS320F2808. The control block diagram consists of two feedback loops, that is, an inner current loop and an outer voltage loop. The outer voltage loop is to regulate the output voltage $V_{O}$ and to generate the current command for the inner current loop. The inner current loop is to control the inductor current and to generate the reference voltage of the PWM generator which supplies the PWM gate signal to each MOSFET switch.

Fig. 14 (a) shows the measured voltage $V_{S 1}$ and the current $i_{S 1}$ waveform of the switch $S_{1}$. Fig. 14 (b) and (c) show zoomed up waveforms during the turn-on interval and the turn-off interval, respectively. Fig. 15 (a) shows the measured voltage $V_{S 2}$ and the current $i_{S 2}$ waveform of the switch $S_{2}$. Fig. 15 (b) and (c) show zoomed up waveforms during the turn-on interval and the turn-off interval, respectively. They prove that the proposed converter achieves good ZVS by using the ARCPC circuit.

Fig. 16 shows the measured current waveforms $i_{L 1}, i_{L 2}$ of the inductors $L_{1}$ and $L_{2}$. It shows that the proposed converter is very well controlled through the PWM method.

Fig. 17 shows the measured current $i_{L r}$ of the auxiliary resonant inductor $L_{r}$ and the gate voltage $V_{G S}\left(S_{a}\right)$ of the auxiliary switch $S_{a}$. As shown in Fig. 17, the resonant inductor current increases above zero after turning on the auxiliary switch $S_{a}$, and then it returns to zero before turning it off. It proves that the auxiliary switch also achieves good ZCS operation.

Fig. 18 shows the measured efficiency of the proposed converter. It shows that the proposed converter has good (a)

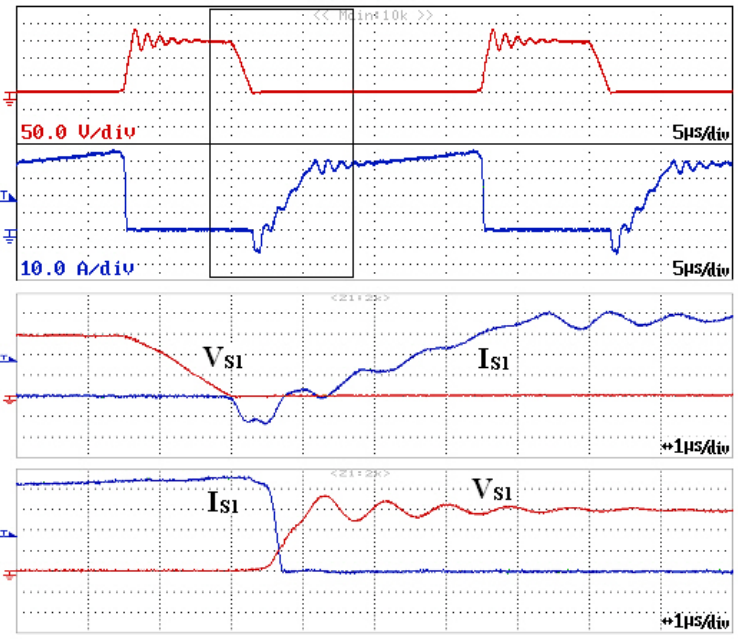

Fig. 14. (a) Voltage $V_{S 1}$ and current $I_{S 1}$ waveforms of switch $S_{1}$, (b) during turn-on interval, (c) during turn-off interval.

(a)

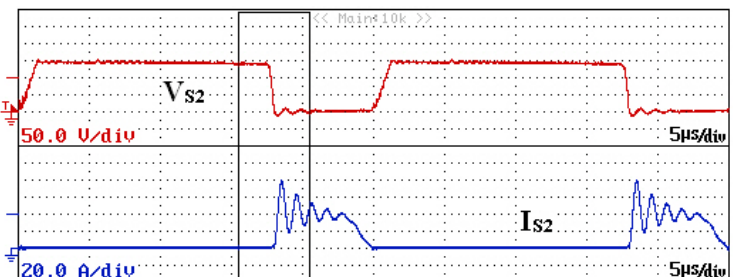

(b)

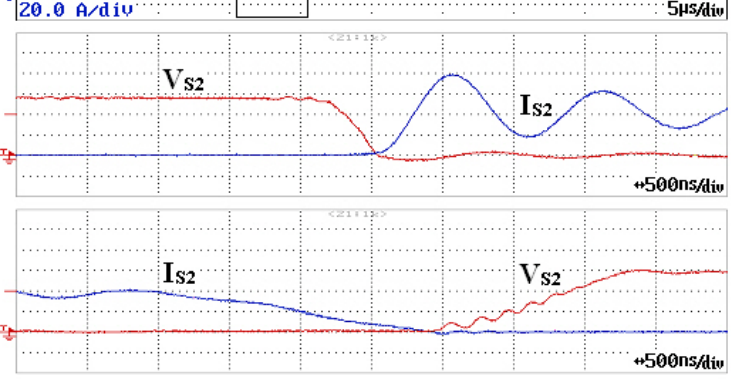

Fig. 15. (a) Voltage $V_{S 2}$ and current $I_{S 2}$ waveform of switch $S_{2}$, (b) during turn-on interval, (c) during turn-off interval.

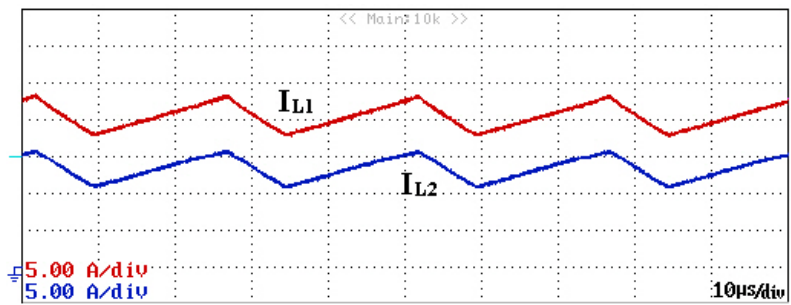

Fig. 16. Current waveforms $i_{L 1}, i_{L 2}$ of inductors $L_{1}$ and $L_{2}$.

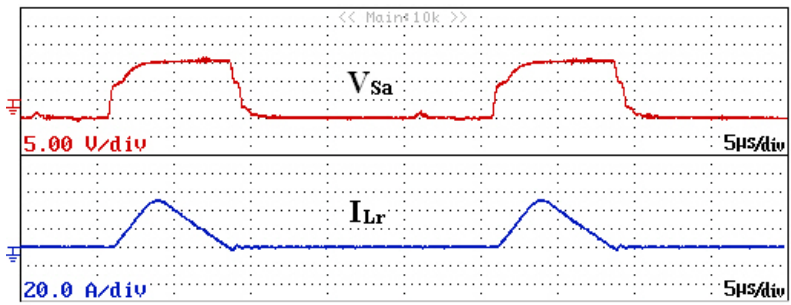

Fig. 17. Current $i_{L r}$ of auxiliary resonant inductor $L_{r}$ and gate voltages $V_{G S}\left(S_{a}\right)$ of auxiliary switches $S_{a}$. 


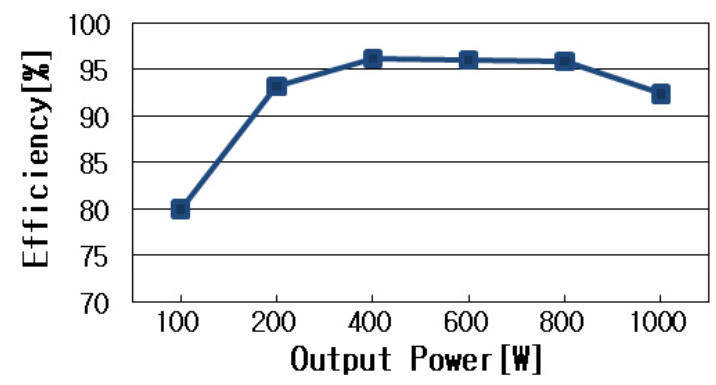

Fig. 18. The measured efficiency of the proposed converter.

efficiency.

\section{Vi. CONCLUSions}

This paper proposes a new ZVS PWM Sepic dc-dc converter. The proposed converter not only has the capability of bilateral power flow, but it also has low switching losses and conduction losses due to its zero voltage switching and synchronous rectifier operation. Furthermore, thanks to the positive and buck/boost-like DC voltage transfer function $(\mathrm{M}=\mathrm{D} /(1-\mathrm{D}))$, the proposed converter is desirable for use in distributed power systems, battery charger/dischargers, dc uninterruptible power supplies, etc. The paper also suggests some design guidelines for the power circuit and the control loop of the proposed converter.

\section{ACKNOWLEDGMENT}

This work was supported by a Pukyong National University Research Fund in 2008 (PK-2008-031).

\section{REFERENCES}

[1] F. Caricchi, F. Crescimbini, and A. Di Napoli, "20kW water-cooled prototype of a buck-boost bidirectional DC-DC converter topology for electrical vehicle motor drives," IEEE APEC Rec., pp. 887-892, 1995.

[2] J. Majo, L. Martinez, A. Poveda, L. Vicuna, F. Guinjoan, A. Sanchez, M. Valentin, and J. Marpinard, "Large-signal feedback control of a bidirectional coupled-inductor cuk converter," IEEE Trans. Industrial Electronics, Vol. 39, No. 5, pp. 429-436, Oct. 1992.

[3] G. Spiazzi and L. Rossetto, "High-quality rectifier based on coupledinductor sepic topology," IEEE PESC Rec., pp. 336-341, 1998.

[4] J. J. Jozwick and M. K. Kazimierczuk, "Dual sepic PWM switchingmode DC/DC power converter," IEEE Trans. on Industrial Electronics, Vol. 36, No. 1, pp.64-70, Feb. 1989.

[5] D. S. L. Simonetti, J. Sebastian, and J. Uceda, "The discontinuous conduction mode sepic and cuk power factor preregulators: Analysis and design," IEEE Trans. Industrial Electronics, Vol. 44, No. 5, pp. 630-637, Oct. 1997.

[6] H. S. Chung, K. K. Tse, S. Y. Hui, C.M. Mok, and M. T. Ho, "A novel maximum power point tracking technique for solar panels using a SEPIC or cuk converter," IEEE Trans. Power Electronics, Vol. 18, No. 3, pp. 717-724, May 2003.

[7] Maged N. F. Nashed, "Design of a digital PWM controller for a soft switching sepic converter," Journal of Power Electronics, Vol. 4, No. 3, pp. 152-160, Jul. 2004.
[8] W.-C. Lee, S.-J. Jang, S.-S. Kim, S.-W. Lee and C.-Y. Won, "A fuel cell generation system with a new active clamp sepic-flyback converter," Journal of Power Electronics, Vol. 9, No. 1, pp. 26-35, Jan. 2009.

[9] R. W. De Doncker and J. P. Lyons, "The auxiliary resonant commutated pole converter," IEEE IAS Rec., pp. 1228-1235, 1990.

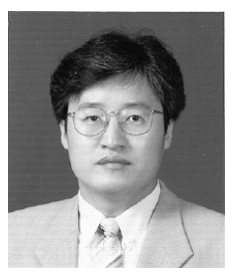

In-Dong Kim received his B.S. in Electrical Engineering from Seoul National University, Seoul, Korea in 1984, and his M.S. and Ph.D. in Electrical and Electronic Engineering from KAIST, Daejeon, Korea in 1987 and 1991, respectively. During 1991-1996, he was a Principal Engineer at the Rolling Stock R\&D Center of Daewoo Heavy Industries, Ltd., Korea. From 1997 to 1998, he did research as a Post Doc. in the Department of Electrical and Computer Engineering, University of Tennessee, Knoxville, USA. From 2004 to 2005, he also served as a Visiting Professor at the Bradley Department of Electrical Engineering, Virginia Tec, Blacksburg, USA. In 1996, he joined the Department of Electrical Engineering, Pukyong National University, Busan, Korea, where he is currently a Full Professor. His current research interests include power electronics, motor drives, power quality control, renewable distributed power sources, and DSP-based control of power converters.

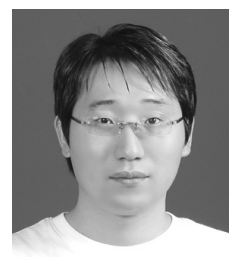

Jin-Young Kim was born in Korea in 1977. He received his B.S. in Electrical Engineering from Pukyong National University, Busan, Korea, in 2004, and his M.S. in Electrical Engineering from Pusan National University, Busan, Korea, in 2006. He is currently working toward his Ph.D. in Electrical Engineering at Pukyong National University, Busan, Korea.

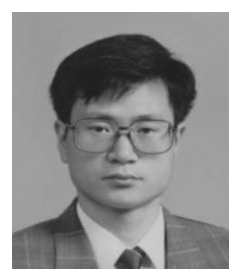

Eui-Cheol Nho received his B.S. in Electrical Engineering from Seoul National University, Seoul, Korea in 1984, and his M.S. and Ph.D. in Electrical and Electronic Engineering from the Korea Advanced Institute of Science and Technology, Daejeon, Korea in 1986 and 1991, respectively. He was with the Powertech Company, Ltd., Korea, as a chief of the R\&D center from 1991 to 1995. In 1995, he joined the Department of Electrical Engineering, Pukyong National University, Busan, Korea, where he is currently a Professor. From 1997 to 1998, he served as a Visiting Scholar in the Department of Electrical and Computer Engineering, University of Wisconsin, Madison. From 2005 to 2006, he also served as a Visiting Scholar in the Department of Electrical Engineering and Computer Science, University of California, Irvine. His current research interests include soft-switching converters, energy storage systems, micro-grid systems, power line conditioners, etc.

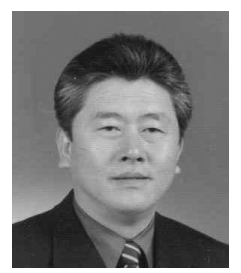

Heung-Geun Kim was born in Korea in 1956. He received his B.S., M.S. and Ph.D. in Electrical Engineering from Seoul National University in 1980, 1982 and 1988, respectively. Since 1984, he has been with the Department of Electrical Engineering at Kyungpook National University, where he is currently a Full Professor and a Director of the Microgrid Research Center. He was with the department of Electrical Engineering at the University of Wisconsin-Madison, as a Visiting Scholar from 1990 to 1991. From 2006 to 2007, he also served as a Visiting Scholar with the Department of Electrical and Computer Engineering at Michigan State University, USA. His current research interests include the control of ac machines and PV power generation. 